\title{
Global optimal control of variable air volume air-conditioning system with iterative learning: an experimental case study*
}

\author{
Qing-long $\mathrm{MENG}^{\dagger 1}$, Xiu-ying YAN ${ }^{\dagger 2}$, Qing-chang $\mathrm{REN}^{2}$ \\ ( ${ }^{1}$ School of Environmental Science and Engineering, Chang'an University, Xi'an 710054, China) \\ ( ${ }^{2}$ School of Information and Control Engineering, Xi'an University of Architecture \& Technology, Xi'an 710055, China) \\ †E-mail: mq119@163.com; xjdyxy1219@163.com \\ Received May 11, 2014; Revision accepted Oct. 29, 2014; Crosschecked Mar. 23, 2015
}

\begin{abstract}
The air-conditioning system in a large commercial or high-rise building is a complex multi-variable system influenced by many factors. The energy saving potential from the optimal operation and control of heating, ventilating, and airconditioning (HVAC) systems can be large, even when they are properly designed. The ultimate goal of optimization is to use the minimum amount of energy needed to improve system efficiency while meeting comfort requirements. In this study, a multizone variable air volume (VAV) and variable water volume (VWV) air-conditioning system is developed. The steady state modes and dynamic models of the HVAC subsystems are constructed. Optimal control based on large scale system theory for system-level energy-saving of HVAC is introduced. Control strategies such as proportional-integral-derivative (PID) controller (gearshift integral PID and self-tuning PID) and iterative learning control (ILC) are studied in the platform to improve the dynamic characteristics. The system performance is improved. An $18.2 \%$ energy saving is achieved with the integration of ILC and sequential quadratic programming based on a steady-state hierarchical optimization control scheme.
\end{abstract}

Key words: Air-conditioning system, Large scale systems, Iterative learning control (ILC), Global optimization doi: $10.1631 /$ jzus.A1400137

Document code: A

CLC number: TK323; TP29

\section{Introduction}

A heating, ventilating, and air-conditioning (HVAC) system is a multi-variable, strongly coupled large scale system composed of several subsystems. Much research has been done on HVAC control, including simulation and experiment. The energy consumption of air-conditioning systems accounts for a large proportion of the total energy consumption in buildings. The adoption of variable air volume (VAV) air-conditioning systems

\footnotetext{
ॠ Corresponding author

* Project supported by the National Natural Science Foundation of China (No. 51208059), the Special Natural Science Research Project of Shaanxi Education Bureau (No. 2013JK1052), and the Special Fund for Basic Scientific Research of Central Colleges, Chang'an University (No. 0009-2014G1291074), China

(D) ORCID: Qing-long MENG, http://orcid.org/0000-0002-3976-2331; Xiu-ying YAN, http://orcid.org/0000-0001-9949-8870

(C) Zhejiang University and Springer-Verlag Berlin Heidelberg 2015
}

reduces energy consumption to some extent. The potential energy savings from the optimal operation and control of HVAC systems can be large, even when they are properly designed. How to implement optimal control for system-level energy-saving while meeting the comfort requirements of a building's occupants is an area of active research. The operating environment (such as the outdoor climate), heating and cooling load (such as the number of occupants in a building), and equipment age result in systems showing macro-repeatability due to seasonal variations and hourly micro-stochastic characteristics. The experience of the operator is a key factor which effects the operation of airconditioning system. However, for complex systems, efficient operation cannot be maintained based on operator experience alone. In the long run, such manual systems are not economical because they operate at very low energy efficiency (Zhang and 
Cai, 2002). Therefore, the adoption of efficient autocontrol strategies for HVAC systems plays a vital role in developing improved energy management and control systems (EMCS) and sustainability (Yan et al., 2010a). Conventional HVAC control methods, such as proportional-integral-differential (PID) controllers, have been popular because of their ease of operation and low initial cost. A single PID controller, however, cannot adapt to multiple system parameters.

As advanced intelligent control and computer technologies have been developed in recent years, methods have been proposed for automating and optimizing EMCS in HVAC systems. Until recently, proposed supervisory control strategies were validated mostly by simulations only. Hu et al. (2005) presented a back-propagation neural network model with five inputs (inlet chilled water temperature, outlet chilled water temperature, inlet temperature of hot air, mass flow rate of chilled water, and mass flow rate of air) and one output (the heat transfer rate) to predict heat exchanger performance. Neural network training was performed using data obtained from a mechanical ventilation and air-conditioning system at the City University of Hong Kong, China. Huang et al. (2006) used outside air economizer cycle, start lead time, stop lead time, load reset, and occupied time adaptive control strategies together as energy management control functions to obtain optimal set points in a VAV-HVAC simulation system. An energy saving of $17 \%$ was achieved compared with the previous system without those functions.

Fong et al. (2006) used an evolutionary programming method to optimize monthly chilled water and air supply temperatures according to the dynamic change in cooling loads and weather conditions. This scheme can result in 7\% energy savings. Barbosa and Mendes (2008) integrated models of a chiller, cooling tower, pumps, coil, humidifier, fan, and mixing box in an HVAC system with models of building hygrothermal to form an innovative overall building hygrothermal and HVAC simulation system. The system combines the simulation of moisture transfer between vapor and liquid phases through the building envelope and the simulation of the HVAC system. During simulation, a MultiTriDiagonal matrix algorithm is used to solve the conservation governing equations. The room temperature changes, moisture accumulation in the building envelope, and energy consumption of the HVAC system are precisely predicted. Simulation results showed that when considering the moisture effects, the energy consumption was $4 \%$ higher than when the moisture effect was disregarded. Mossolly et al. (2009) optimized the fresh air volume, air supply flow rate, and air supply temperature in a multi-zone air-conditioning system using a genetic algorithm (GA), taking the predicted mean vote (PMV) set point inside the conditioned zones as the objective function. This resulted in $30.4 \%$ energy savings during four summer months. Kwok and Lee (2011) established an artificial neural network model which introduces occupancy area and occupancy rate, instead of using fixed historical load data to mimic building occupancy. In this way the accuracy of the cooling load prediction was significantly improved through simulating an office building in Hong Kong. Ma and Wang (2011) presented a GA for optimization of the water supply temperature set point of a condenser, chiller, and heat exchanger for central chiller plants in a simulated virtual system using simplified adaptive models of the main components. This method enhanced daily energy efficiency by about $0.73 \%, 1.35 \%$, and $2.55 \%$ on a sunny summer, mild summer, and spring day, respectively. Wang et al. (2011) presented a demandcontrolled ventilation strategy aiming to optimize the fresh air flow by minimizing energy consumption while meeting the minimum indoor air quality standards, using a least square algorithm.

Few researchers have reported practical validation of supervisory and optimal control methods on real HVAC systems (West et al., 2014), especially large and complicated systems (Wang and Ma, 2008). Some researchers have presented computer models based on laboratory data. Anderson et al. (2007) established models of a blower, mixing box, boiler, water flow damper, heating coil, and the overall system, and presented a multi-input multioutput robust controller for an experimental HVAC system. Simulating a typical existing HVAC system, Nassif and Moujaes (2008) and Nassif (2010) experimented with various damper control strategies, such as three-coupled damper control, two-coupled damper control, and split-signal control, and showed that the selected split control strategy had a significant effect on fan performance and energy use. If properly implemented, the fan can achieve energy savings 
in the range of $5 \%-30 \%$. Cho et al. (2010) minimized the airflow set point of a VAV box to guarantee thermal comfort and reduce energy consumption. The strategy was tested in a five story office building in Omaha, Nebraska, USA. They claimed a reduction of $74.5 \%$ in gas consumption within an eightmonth period. Platt et al. (2010) discussed adaptive HVAC zone modeling and zone model fitting using a GA for time-variant zones, validated by experimental measurements. Their technique can adapt to both short and long term load changes.

A recent trend is the system-level optimization of parameters in the HVAC system, such as air supply temperature, duct static pressure, and chilled water temperature, which aims to achieve global optimization of the entire HVAC system rather than that of individual subsystems/parameters, taking into account their complex interactions. Yan et al. (2010) adopted an interaction balance coordination method to achieve global energy savings. Kusiak et al. (2011) presented multi-objective optimization of an HVAC system with the objectives of minimizing energy consumption and maximizing indoor air quality (IAQ). The set points of air supply temperature and air supply duct static pressure are generated by a GA, resulting in energy savings of $21.4 \%$ without violating the IAQ constraints, and $22.6 \%$ when occasionally violating the IAQ.
In this study, we described the experimental platform and provided a detailed description of the models of different control loops, the building mode approach, and control strategies in HVAC systems.

\section{Experimental platform}

In commercial buildings, HVAC systems usually contain a supply fan to provide sufficient air volume at a controlled temperature for cooling or heating. A cooling/heating exchange coil is necessary in the air handling unit (AHU) for this purpose. Pumps and water dampers are used to regulate the water flow through the cooling/heating coil and to control the air supply temperature. The air flow rate may be constant or variable. For large buildings, the platform is divided into several zones so that the temperature within each zone can be controlled independently.

\subsection{Hardware}

A schematic diagram of the VAV airconditioning system developed in this research is shown in Fig. 1. The system consists of a water system (Fig. 1, left) and an air side system (Fig. 1, right). The air side system includes two air handling units (AHUA and AHUB) and six VAV boxes with

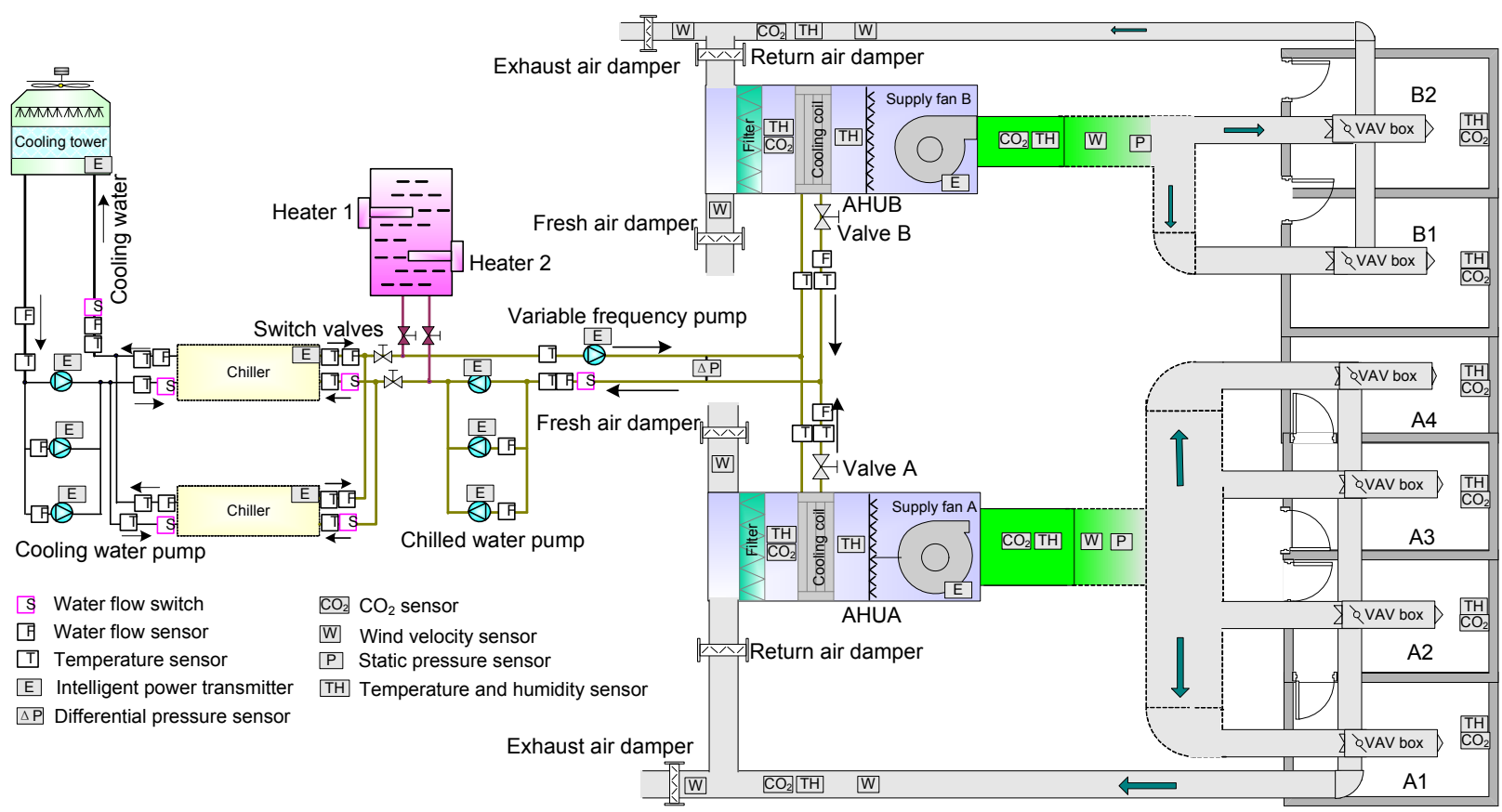

Fig. 1 Schematic of the VAV air-conditioning system 
two variable speed air supply fans A and B (one for each AHU), exhaust fans, and supply, return, and exhaust dampers. Each VAV box contains two reheaters that are used to moderate the temperature discharged into the rooms. The water system is composed of a cold source and a heating source. The cold source is composed of two chillers (each with one chilling pump), two cooling pumps, one secondary variable speed pump, and one cooling tower. The heating source includes one heating box with two heaters. There are two switch dampers between the cold source and the heat source in the pipeline. They are used to change the cooling condition in the summer to the heating condition in the winter, and vice versa.

The experimental platform is a multi-zone VAV and variable water volume (VAV-VWV) airconditioning system. There are six test rooms identified as A1-A4 and B1 and B2 (Fig. 1, right). The six rooms are separated by insulation steel plate with polyurethane foam inside. The rooms have interior walls only (they are not adjacent to any exterior wall), so they are not affected by solar radiation. AHUA is responsible for rooms A1-A4, and AHUB for rooms B1 and B2.

Fig. 2 shows the three-level network structure of the HVAC control. The first (top) level is the management level. The second (middle) level is the optimization and control level while the third (bottom) level is the field control level. Three industrial computers are connected through the industrial Ethernet to communicate with the Ethernet unit in the platform. The local operating network maker
(LonMaker) system is installed in the computer on the left. The computer in the middle is treated as the host. The control and optimization strategies are implemented in laboratory virtual instrument engineering workbench (LabVIEW) (Blume, 2007) software. Data acquisition and transmission of control signals are implemented by a serial communication unit. All the field devices can be controlled on the basis of functional requirements.

\subsection{Software}

Control strategies for air quality and thermal comfort (especially for $\mathrm{CO}_{2}$ and indoor temperature) are implemented through the software. To implement various tests, monitoring and control interface software was developed in the LabVIEW environment. The overall software structure is shown in Fig. 3. The monitoring system is composed of an air-conditioning control system (ACS), energy measurement system (EMS), and data query system (DQS).

The ACS consists of two subsystems. One is a closed monitoring control system (CMC) developed using programmable logic controller (PLC). It controls the air-conditioning system using classical control methods such as PID. Misuse and man-made accidents are avoided because the system is closed. System information can be stored in DQS. The other subsystem is a research monitoring system (RMS) developed using PLC, LabVIEW, and MATLAB. It can call MATLAB programs in LabVIEW for advanced control. All the detection and control signals are transferred through PLC modules. Within PLC,

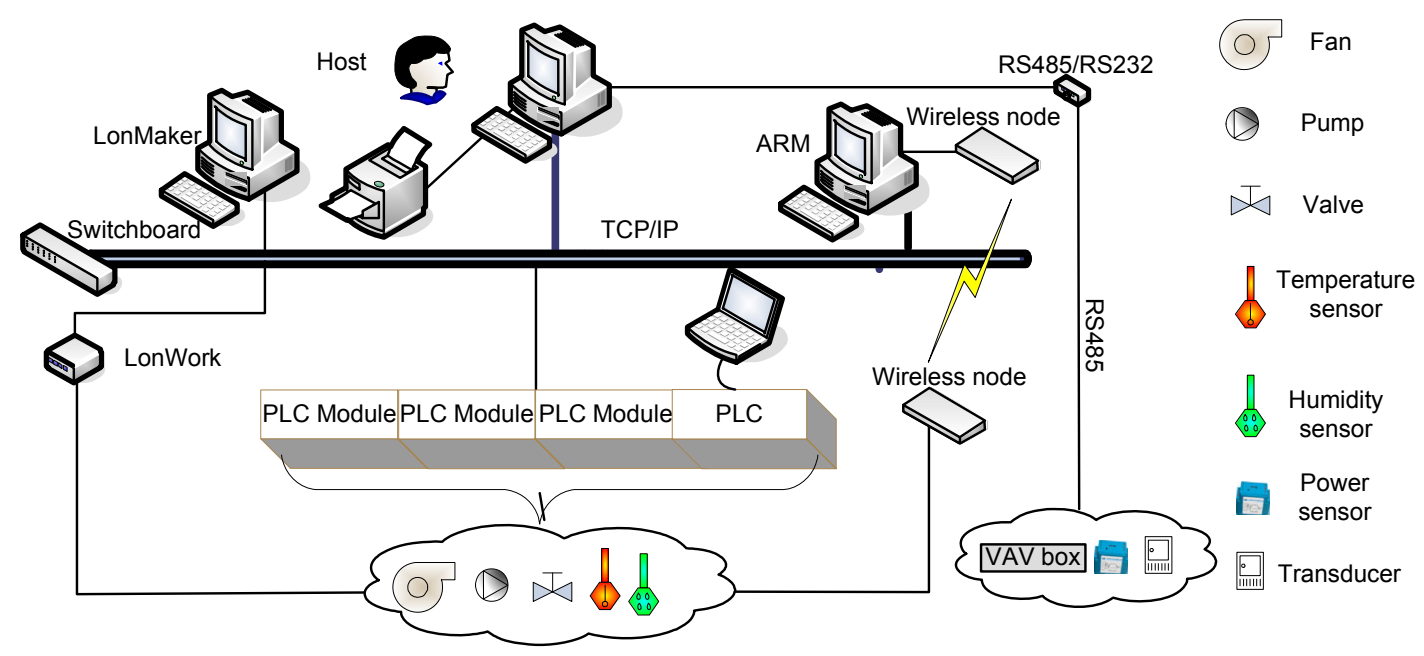

Fig. 2 Network structure of the HVAC system 


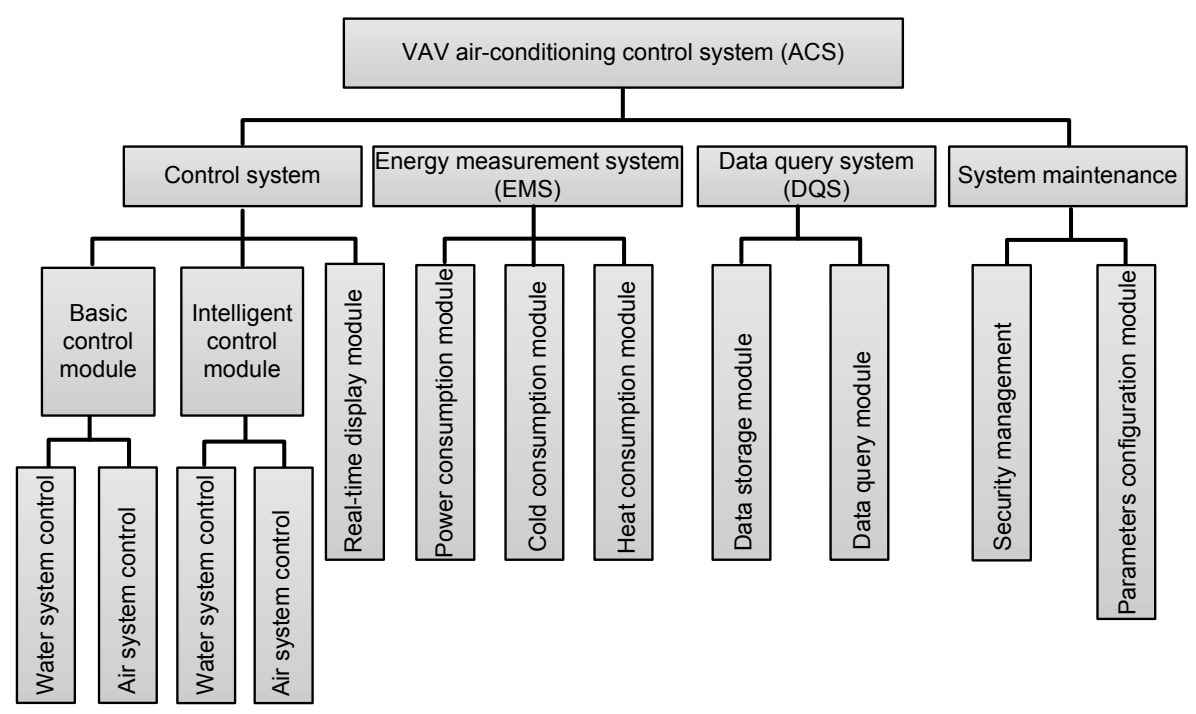

Fig. 3 Overall software structure

there is only interlocking protection programming. Modeling and control strategies are implemented in LabVIEW and MATLAB. The second monitoring subsystem was used in this study.

\section{Optimization, models, and control strategies}

\subsection{Optimization}

The HVAC system is composed of five subsystems: AHUA, AHUB, Terminal A, Terminal B, and the water system. To optimize the full system, the hierarchical optimization structure is adopted, which is shown in Fig. 4. The optimization system is divided into three layers from top to bottom: coordinator layer, optimization layer, and direct control layer (DCL) (Yan et al., 2010a).

With interaction balance method (IBM), the coordinator layer could compute the coordination variable $\lambda$ for the local decision making units (LDMU) of the optimization layer. The optimization layer is responsible for search of optimal decisions with $\lambda$. The bottom layer could track the desired trajectories from the LDMU, in which iterative learning control (ILC) was adopted to obtain set point series. The interconnection matrix (IM) includes the interaction information of the subsystem inputs and outputs. $\boldsymbol{c}_{i}, \boldsymbol{u}_{i}$, and $\boldsymbol{y}_{i}(i=1,2,3,4,5)$ represents the control signal, interconnection input and output for subsystem $i$, respectively. $\lambda_{i}(i=1,2,3,4,5)$ is the Lagrange multiplier. ${ }^{\wedge}$ indicates the calculated

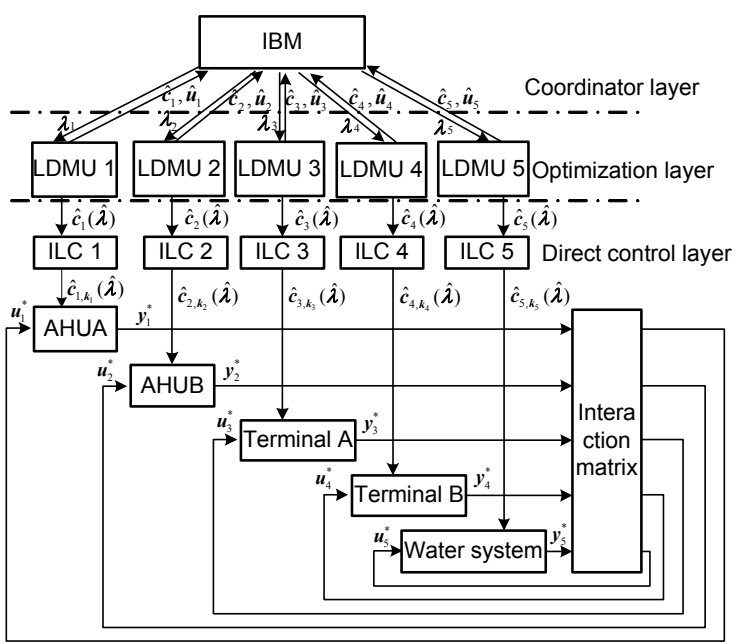

Fig. 4 Control hierarchical structure of air-conditioning system

parameters, while ${ }^{*}$ represents the real system's parameters. $k_{i}$ denotes the control number of the $i$ th subsystem. $\hat{\boldsymbol{c}}_{i, k_{i}}(i=1,2,3,4,5)$ is the ILC output for the $i$ th subsystem. Then, the system can be written as

$$
\begin{aligned}
\boldsymbol{y}_{i} & =\boldsymbol{A}_{i} \boldsymbol{c}_{i}+\boldsymbol{B}_{i} \boldsymbol{u}_{i}, \quad i=1,2,3,4,5, \\
\boldsymbol{u}_{i} & =\sum_{j=1}^{5} \boldsymbol{H}_{i j} \boldsymbol{y}_{j}, \quad i=1,2,3,4,5,
\end{aligned}
$$

where $\boldsymbol{H}_{i j}$ is the IM that denotes the impact of subsystem $i$ on the subsystem $j . \boldsymbol{A}_{i}$ is the state matrix for subsystem $i$ while $\boldsymbol{B}_{i}$ is the control matrix.

In the system, there are five subsystems, let 


$$
\boldsymbol{H}=\left[\begin{array}{ccc}
\boldsymbol{H}_{11} & \ldots & \boldsymbol{H}_{15} \\
\vdots & & \vdots \\
\boldsymbol{H}_{51} & \cdots & \boldsymbol{H}_{55}
\end{array}\right],
$$

where $\boldsymbol{H}$ is the coupling correlation matrix set. The objective function of subsystem $i$ for the LDMU is $O_{i}\left(\boldsymbol{c}_{i}, \boldsymbol{u}_{i}, \boldsymbol{y}_{i}\right)$. The total objective function is

$$
O(\boldsymbol{c}, \boldsymbol{u}, \boldsymbol{y})=\sum_{i=1}^{5} O_{i}\left(\boldsymbol{c}_{i}, \boldsymbol{u}_{i}, \boldsymbol{y}_{i}\right) .
$$

When the Lagrange multiplier $\lambda$ is introduced under constraint $\boldsymbol{u}=\boldsymbol{H} \boldsymbol{y}$, The index of the Lagrange coordinator function $L$ can be written as

$$
L=\sum_{i=1}^{N} L_{i}=\sum_{i=1}^{N}\left\{O_{i}\left(\boldsymbol{c}_{i}, \boldsymbol{u}_{i}, \boldsymbol{y}_{i}\right)+\lambda_{i}^{\mathrm{T}} \boldsymbol{u}_{i}-\sum_{j=1}^{N} \lambda_{j}^{\mathrm{T}} \boldsymbol{H}_{j i} \boldsymbol{y}_{i}\right\},
$$

where $L_{i}$ is the amended performance criteria for system $i$.

So the coordinator searches the coordination variable $\lambda_{i}$. LDMU finds the suitable $\boldsymbol{c}_{i}, \boldsymbol{u}_{i}$ to minimize $L_{i}$.

Here, the optimal start-stop time schedules were considered to ensure long serviceability of the equipment $D_{\mathrm{he}, 1}, D_{\mathrm{he}, 2}$, and $D_{\mathrm{he}, 3}$.

Based on the characteristics of the HVAC system in intelligent building environment technology experiment flat, the parameters to be optimized include:

(1) Air supply temperature of the AHUA and AHUB, $T_{\text {sua, } \mathrm{A}}$ and $T_{\text {sua, }}$;

(2) Air supply static pressure $p_{\text {staic,A, }}, p_{\text {staic }, \mathrm{B}}$;

(3) Water supply temperature $T_{\text {suw h, }}$;

(4) Pressure difference of supply-return water $\Delta p_{\mathrm{w}}$.

The optimal time schedule should be adopted to ensure long serviceability of the equipment $D_{\mathrm{he}, 1}$, $D_{\mathrm{he}, 2}$, and $D_{\mathrm{he}, 3}$. If in the summer condition, more variables should be considered.

The performance criteria are

$$
O(\boldsymbol{c}, \boldsymbol{u}, \boldsymbol{y})=E_{\mathrm{fan}, \mathrm{A}}+E_{\mathrm{fan}, \mathrm{B}}+E_{\text {heater } 1}+E_{\text {heater } 2}+E_{\mathrm{pp}},
$$

where $E_{\text {fan, } \mathrm{A}}, E_{\text {fan, } \mathrm{B}}, E_{\text {heater } 1}, E_{\text {heater } 2}$, and $E_{\mathrm{pp}}$ represents the energy consumption of fans in AHUA, AHUB, heater 1, heater 2, and pumps, respectively.

Constraints are:

$$
\begin{aligned}
& 30 \mathrm{~Hz} \leq f_{\mathrm{a}, \text { fan }} \leq 50 \mathrm{~Hz}, \quad 0 \% \leq C_{\mathrm{dp}} \leq 100 \% \text {, } \\
& 0 \% \leq \mathrm{Va} \leq 100 \%, \quad 11^{\circ} \mathrm{C} \leq T_{\text {sua }} \leq 20^{\circ} \mathrm{C}, \\
& 0 \leq F_{\text {suw,ch }} \leq 2.5 \mathrm{~m}^{3} / \mathrm{h} \text {, } \\
& Q_{\text {coil, } \mathrm{A}}=W_{\mathrm{a}, \mathrm{A}} C_{\mathrm{p}, \mathrm{a}}\left(T_{\text {mix }, \mathrm{A}}-T_{\text {sua } \mathrm{A}}\right) \\
& =F_{\text {suw,ch,AHA }} C_{\mathrm{P}, \mathrm{w}}\left(T_{\text {rew,ch, } \mathrm{A}}-T_{\text {suw,ch }}\right) \\
& =U A_{\mathrm{o}}\left[\left(T_{\text {mix }, \mathrm{A}}-T_{\text {rew,ch, } \mathrm{A}}\right)-\left(T_{\text {sua, } \mathrm{A}}-T_{\text {suw, ch }}\right)\right] \\
& /\left[\ln \left(T_{\text {mix }, \mathrm{A}}-T_{\text {rew,ch, } \mathrm{A}}\right)-\ln \left(T_{\text {sua } \mathrm{A}}-T_{\text {suw }, \mathrm{ch}}\right)\right] \text {, } \\
& Q_{\text {coil, } \mathrm{B}}=W_{\mathrm{a}, \mathrm{B}} C_{\mathrm{p}, \mathrm{a}}\left(T_{\text {mix, } \mathrm{B}}-T_{\text {sua, } \mathrm{B}}\right) \\
& =F_{\text {suw,ch, } \mathrm{AHB}} C_{\mathrm{P}, \mathrm{w}}\left(T_{\text {rew,ch, } \mathrm{B}}-T_{\text {suw,ch }}\right) \\
& =U A_{\mathrm{o}}\left[\left(T_{\text {mix }, \mathrm{B}}-T_{\text {rew,ch, } \mathrm{B}}\right)-\left(T_{\text {sua, } \mathrm{B}}-T_{\text {suw }, \mathrm{ch}}\right)\right] \\
& /\left[\ln \left(T_{\text {mix, } \mathrm{B}}-T_{\text {rew,ch, } \mathrm{B}}\right)-\ln \left(T_{\text {sua, } \mathrm{B}}-T_{\text {suw,ch }}\right)\right] \text {, }
\end{aligned}
$$

where $f_{\mathrm{a} \text {,fan }}$ is the frequency of supply fan $(\mathrm{Hz}) ; C_{\mathrm{dp}}$ is the opening of dampers; Va represents the opening of valves in the system; $Q_{\text {coil,A }}$ and $Q_{\text {coil,B }}$ represents the energy of coil in AHUA and AHUB (kW); $W_{\mathrm{a}, \mathrm{A}}$ and $W_{\mathrm{a}, \mathrm{B}}$ is the air flow rate of AHUA and AHUB $(\mathrm{kg} / \mathrm{s}) ; C_{\mathrm{p}, \mathrm{a}}$ and $C_{\mathrm{P}, \mathrm{w}}$ is the specific heat of air and water; $T_{\mathrm{mix}, \mathrm{A}}$ and $T_{\mathrm{mix}, \mathrm{B}}$ is the temperature in the mixing box of AHUA and AHUB $\left({ }^{\circ} \mathrm{C}\right) ; T_{\text {rew,ch,A }}$ and $T_{\text {rew,ch,B }}$ is return chilled water temperature of AHUA and AHUB $\left({ }^{\circ} \mathrm{C}\right)$, respectively; $T_{\text {suw,ch }}$ is the supply chilled water temperature $\left({ }^{\circ} \mathrm{C}\right) ; F_{\text {suw,ch,AHA }}$ and $F_{\text {suw,ch,AHB }}$ represents the volume of supply chilled water in AHUA and AHUB $\left(\mathrm{m}^{3} / \mathrm{h}\right)$, respectively; $U$ is the total heat exchange coefficient $\left(\mathrm{kW} /\left(\mathrm{m}^{2} \cdot{ }^{\circ} \mathrm{C}\right)\right)$; and $A_{\mathrm{o}}$ is the external heat exchange area $\left(\mathrm{m}^{2}\right)$. The sequential quadratic programming method is used in the LDMU as it can solve nonlinear programs directly. Based on the characteristics of the HVAC system, the optimization period is $30 \mathrm{~min}$.

\subsection{Models of the plant}

A VAV air-conditioning system is a typical distributed parameter system with strong nonlinear characteristics. It is hard to establish mechanistic models of such an air-conditioning system because of its complex and multi-variable nature (Afram and JanabiSharifi, 2014). In this research, a system identification approach was used to model the system and estimate its parameters. The following simplifications were made: (i) all equipment was insulated; (ii) there was no heat transfer between fans and pumps; (iii) the air state in the duct and each room was the same so that the system could be treated as a lumped parameter system; (iv) the kinetic and potential energies of 
air molecules were insignificant and neglected; (v) the influence of moisture in the air was ignored.

\subsubsection{Steady state models}

The steady state separable models were obtained through the large scale system theory decentralized identification method. The parameters of each subsystem in Fig. 4 were determined. The decentralized steady state models were as follows:

$$
\begin{aligned}
& \boldsymbol{c}_{1}=\left[c_{11}, c_{12}, c_{13}, c_{14}, c_{15}, c_{16}\right]^{\mathrm{T}} \\
& =\left[\mathrm{Va}_{\mathrm{A}}, f_{\mathrm{a}, \mathrm{A} \text { fan }}, C_{\mathrm{dp}, \mathrm{fre}, \mathrm{A}}, C_{\mathrm{dp}, \mathrm{re}, \mathrm{A}}, C_{\mathrm{dp}, \mathrm{ex}, \mathrm{A}}, D_{\mathrm{hu}, \mathrm{A}}\right]^{\mathrm{T}} \text {, } \\
& \boldsymbol{u}_{1}=\left[u_{11}, u_{12}, u_{13}, u_{14}, u_{15}, u_{16}, u_{17}, u_{18}\right]^{\mathrm{T}} \\
& =\left[T_{\text {suv,ch }}, F_{\text {sur,ch,AHA }}, T_{\text {fre }}, T_{\text {re,A }}, \mathrm{CO}_{2 \text { fre }}, \mathrm{CO}_{2 \text { re,A }}, H_{\text {fre }}, H_{\mathrm{re}, \mathrm{A}}\right]^{\mathrm{T}} \text {, } \\
& \boldsymbol{y}_{1}=\left[y_{11}, y_{12}, y_{13}, y_{14}, y_{15}, y_{16}, y_{17}\right]^{\mathrm{T}}
\end{aligned}
$$

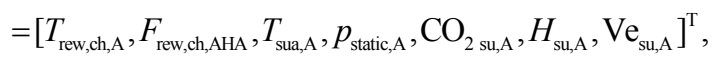

$$
\begin{aligned}
& \boldsymbol{c}_{2}=\left[c_{21}, c_{22}, c_{23}, c_{24}, c_{25}, c_{26}\right]^{\mathrm{T}} \\
& =\left[\mathrm{Va}_{\mathrm{B}}, f_{\mathrm{a}, \mathrm{B} \text {,fan }}, C_{\mathrm{dp}, \mathrm{fre}, \mathrm{B}}, C_{\mathrm{dp}, \mathrm{re}, \mathrm{B}}, C_{\mathrm{dp}, \mathrm{ex}, \mathrm{B}}, D_{\mathrm{hu}, \mathrm{B}}\right]^{\mathrm{T}} \text {, } \\
& \boldsymbol{u}_{2}=\left[u_{21}, u_{22}, u_{23}, u_{24}, u_{25}, u_{26}, u_{27}, u_{28}\right]^{\mathrm{T}} \\
& =\left[T_{\text {suv,ch }}, F_{\text {suw,ch, } A \text { AHB }}, T_{\text {fre }}, T_{\text {re, B }}, \mathrm{CO}_{2 \text { fre }}, \mathrm{CO}_{2 \text { re, B }}, H_{\text {fre }}, H_{\text {re, },}\right]^{\mathrm{T}} \text {, } \\
& \boldsymbol{y}_{2}=\left[y_{21}, y_{22}, y_{23}, y_{24}, y_{25}, y_{26}, y_{27}\right]^{\mathrm{T}} \\
& =\left[T_{\text {rew,ch, }, \mathrm{B}}, F_{\text {rew,ch,AHB }}, T_{\text {sua, },}, p_{\text {static, },}, \mathrm{CO}_{2 \text { su, }}, H_{\text {su, }}, \mathrm{Ve}_{\text {su, }}\right]^{\mathrm{T}} \text {, } \\
& \boldsymbol{c}_{3}=\left[c_{31}, c_{32}, c_{33}, c_{34}, c_{35}, c_{36}, c_{37}, c_{38}\right]^{\mathrm{T}} \\
& =\left[C_{\mathrm{dp}, \mathrm{r}, 1}, C_{\mathrm{dp}, \mathrm{r}, 2}, C_{\mathrm{dp}, \mathrm{r}, 3}, C_{\mathrm{dp}, \mathrm{r}, 4}, D_{\mathrm{he}, \mathrm{b}, 1}, D_{\mathrm{he}, \mathrm{b}, 2}, D_{\mathrm{he}, \mathrm{b}, 3}, D_{\mathrm{he}, \mathrm{b}, 4}\right]^{\mathrm{T}} \text {, } \\
& \boldsymbol{u}_{3}=\left[u_{31}, u_{32}, u_{33}, u_{34}\right]^{\mathrm{T}}=\left[T_{\mathrm{suaA}, \mathrm{A}}, H_{\mathrm{su}, \mathrm{A}}, \mathrm{CO}_{2 \mathrm{su}, \mathrm{A}}, \mathrm{Ve}_{\mathrm{su}, \mathrm{A}}\right]^{\mathrm{T}} \text {, } \\
& \boldsymbol{y}_{3}=\left[y_{31}, y_{32}, y_{33}, y_{34}, y_{35}, y_{36}, y_{37}, y_{38}, y_{39}, y_{310}, y_{311}, y_{312}\right]^{\mathrm{T}} \\
& =\left[T_{\mathrm{r}, 1}, T_{\mathrm{r}, 2}, T_{\mathrm{r}, 3}, T_{\mathrm{r}, 4}, H_{\mathrm{r}, 1}, H_{\mathrm{r}, 2}, H_{\mathrm{r}, 3}, H_{\mathrm{r}, 4},\right. \\
& \left.\mathrm{CO}_{2 \mathrm{r}, 1}, \mathrm{CO}_{2 \mathrm{r}, 2}, \mathrm{CO}_{2 \mathrm{r}, 3}, \mathrm{CO}_{2 \mathrm{r}, 4}\right]^{\mathrm{T}} \text {, } \\
& \boldsymbol{c}_{4}=\left[c_{41}, c_{42}, c_{43}, c_{44}\right]^{\mathrm{T}}=\left[C_{\mathrm{dp}, 5,5}, C_{\mathrm{dp}, \mathrm{r}, 6}, D_{\mathrm{he}, \mathrm{b}, 5}, D_{\mathrm{he}, \mathrm{b}, 6}\right]^{\mathrm{T}} \text {, } \\
& \boldsymbol{u}_{4}=\left[u_{41}, u_{42}, u_{43}, u_{44}\right]^{\mathrm{T}}=\left[T_{\mathrm{suaA}, \mathrm{A}}, H_{\mathrm{su}, \mathrm{A}}, \mathrm{CO}_{2 \mathrm{su}, \mathrm{A}}, \mathrm{Ve}_{\mathrm{su}, \mathrm{A}}\right]^{\mathrm{T}} \text {, } \\
& \boldsymbol{y}_{4}=\left[y_{41}, y_{42}, y_{43}, y_{44}, y_{45}, y_{46}\right]^{\mathrm{T}} \\
& =\left[T_{\mathrm{r}, 5}, T_{\mathrm{r}, 6}, H_{\mathrm{r}, 5}, H_{\mathrm{r}, 6}, \mathrm{CO}_{2 \mathrm{r}, 5}, \mathrm{CO}_{2 \mathrm{r}, 6}\right]^{\mathrm{T}} \text {, } \\
& \boldsymbol{c}_{5}=\left[c_{51}, c_{52}, c_{53}, c_{54}, c_{55}, c_{56}, c_{57}, c_{58}, c_{59}, c_{510}, c_{511}\right]^{\mathrm{T}} \\
& =\left[D_{\mathrm{ch}, \mathrm{A}}, D_{\mathrm{ch}, \mathrm{B}}, D_{\mathrm{pp}, \mathrm{col} 1}, D_{\mathrm{pp}, \mathrm{co2} 2}, D_{\mathrm{pp}, \mathrm{co3}},\right. \\
& \left.D_{\mathrm{pp}, \mathrm{ch} 1}, D_{\mathrm{pp}, \mathrm{ch} 2}, D_{\mathrm{pp}, \mathrm{ch} 3}, f_{\mathrm{w}, \text { sec,pump }}, \mathrm{Va}_{\mathrm{by}}\right]^{\mathrm{T}} \text {, } \\
& \boldsymbol{u}_{5}=\left[u_{51}, u_{52}, u_{53}, u_{54}, u_{55}, u_{56}\right]^{\mathrm{T}}
\end{aligned}
$$

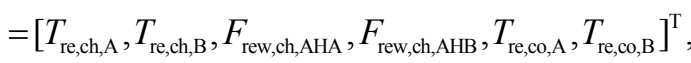

$$
\begin{aligned}
& \boldsymbol{y}_{5}=\left[y_{51}, y_{52}, y_{53}, y_{54}, y_{55}, y_{56}, y_{57}, y_{58}\right]^{\mathrm{T}} \\
& =\left[T_{\text {suw,ch, } \mathrm{A}}, T_{\text {suv, }, \mathrm{ch}, \mathrm{B}}, F_{\text {suw,ch, }, \mathrm{AHA}}, F_{\text {suw,ch, } \mathrm{AHB}},\right. \\
& \left.\Delta p_{\text {w }}, T_{\text {suw }, \mathrm{co}, \mathrm{A}}, T_{\text {suv }, \mathrm{co}, \mathrm{B}}, \Delta p_{\text {by }}\right]^{\mathrm{T}} \text {, }
\end{aligned}
$$

$$
\begin{aligned}
\boldsymbol{c}_{5}^{\prime} & =\left[c_{51}^{\prime}, c_{52}^{\prime}, c_{53}^{\prime}, c_{54}^{\prime}\right]^{\mathrm{T}}=\left[D_{\mathrm{he}, 1}, D_{\mathrm{he}, 2}, D_{\mathrm{he}, 3}, f_{\mathrm{w}, \text { sec,pump }}\right]^{\mathrm{T}}, \\
\boldsymbol{u}_{5}^{\prime} & =\left[u_{51}^{\prime}, u_{52}^{\prime}\right]^{\mathrm{T}}=\left[T_{\mathrm{rech}, \mathrm{A},}, T_{\mathrm{rech}, \mathrm{B}, \mathrm{B}}\right]^{\mathrm{T}}, \\
\boldsymbol{y}_{5}^{\prime} & =\left[y_{51}^{\prime}, y_{52}^{\prime}, y_{53}^{\prime}\right]^{\mathrm{T}}=\left[T_{\text {suv,he }}, T_{\text {suw }, \mathrm{he}}, \Delta p_{\mathrm{w}}\right]^{\mathrm{T}},
\end{aligned}
$$

where the subscripts fre, ex, hu, r, re, pp, co, sec, w, suw, by, and he represents the fresh air, exhaust air, humidifier, room, return, pump, cooling, secondary, water, supply water, bypass, and heat, respectively. $\mathrm{Ve}$ is the average velocity of system $(\mathrm{m} / \mathrm{s}) . \mathrm{CO}_{2}$ is the concentration of carbon dioxide (ppm). $D$ is the start-stop signal. $\boldsymbol{c}_{5}{ }^{\prime}, \boldsymbol{u}_{5}{ }^{\prime}$, and $\boldsymbol{y}_{5}{ }^{\prime}$ denote the cooling condition in the summer but the heating condition in the winter.

\subsubsection{Dynamic models}

The control loops identified in this study were simplified as single input single output linear systems without interactions among them. The interactions in the upper optimization layer of the hierarchical control structure were considered in (Yan et al., 2010a).

The secondary variable frequency pump's (Fig. 1) differential pressure and static pressure in the main duct, and the air supply temperature in each AHU of the air-conditioning system were the control and optimization variables in this research. In the test, the system inputs were the frequency of the secondary pump, frequencies of the supply fans, and the size of the water damper opening, which were input through the monitoring interface. Pseudorandom binary signal (PRBS) (Lennart, 1999) was chosen for input signal to avoid disturbances. PRBS is a stationary stochastic process signal with cyclical periods. The autocorrelation function of PRBS resembles that of white noise. The dynamic characteristics of the system can be persistently excited with PRBS, so that there will be a unique solution of estimation. A type of PRBS, inverse maximum length sequence (IMS) (Lennart, 1999), was used as input signal. Through measuring the inputs and outputs of the control loops, sampling data was acquired for identification. Using the adaptive directional forgetting (ADF) method (Kulhavý, 1987), the following models were acquired.

1. Secondary pump differential pressure model

Here, the secondary pump was a variable-speed pump and its speed was adjusted according to the load to maintain the water flow. The differential pressure of the secondary pump was selected as the 
controlled parameter. The frequency of the secondary pump was the control variable. The model is shown below and the control effect will be discussed in the results section. In this loop, the sample time was $1 \mathrm{~s}$.

$$
G(s)=\frac{0.00007586 s^{2}-0.000799 s+0.001294}{s^{2}+2.589 s+1.178},
$$

where $G(s)$ is transfer function of the process, $s$ is a complex argument which is Laplace transform factor.

2. Air supply air temperature control

The VAV air-conditioning system uses a fixed air supply temperature. To control the temperature of the air supply, the water damper opening must be regulated to adjust the water volume on the AHU side. Thus, the energy exchanged between the water and the air supply can be adjusted according to the load change. For the purpose of saving energy, the air supply temperature must be reasonably determined during operating. The optimization of the air supply temperature set point can solve this problem to some extent. The air supply temperature model is needed in the optimization process. One of the identified models is

$$
\begin{aligned}
G(s)= & \left(0.0003157 s^{4}-6.027 \times 10^{-5} s^{3}\right. \\
& \left.+3.923 \times 10^{-6} s^{2}-1.074 \times 10^{-7} s+1.063 \times 10^{-9}\right) \\
& /\left(s^{4}+0.1001 s^{3}+0.003338 s^{2}+3.72 \times 10^{-5} s\right. \\
& \left.+1.855 \times 10^{-9}\right) .
\end{aligned}
$$

\section{Static pressure control model}

To guarantee the room air temperature, there should be enough volume in the air supply. This means the duct static pressure must be high enough, but not too high, to avoid wastage. The duct static pressure is related to the supply fan speed and the damper openings in the VAV box. The effect of damper openings in the VAV box was not considered in the single loop but was considered in the interaction part in the overall system. In this control loop, the controlled parameter was static pressure in the duct. The control variable was supply fan frequency. The fan frequency was taken as the input, and the static pressure as the output. With the inverse $M$ sequence, the sampling time was $2 \mathrm{~s}$. The steady-state frequency of the supply fan in the AHUA was $35 \mathrm{~Hz}$. The model of the fan A-static pressure was acquired as follows:

$$
G(s)=\frac{-0.02761 s^{2}+0.02056 s+0.007049}{s^{2}+0.1993 s+0.002494} .
$$

Using the same method, the model of the fan B-static pressure was acquired:

$$
G(s)=\frac{0.3091 s^{2}-0.5025 s+0.1934}{s^{2}+1.034 s+0.03365} .
$$

\section{Energy consumption models}

All the energy models will be acquired through theory analysis. The variable frequency fan energy model is

$$
E_{\mathrm{fan}}=E_{\mathrm{fan}, \mathrm{A}}+E_{\mathrm{fan}, \mathrm{B}}=\frac{F_{\mathrm{fan}, \mathrm{A}} P_{\mathrm{fan}, \mathrm{A}}}{\eta_{\mathrm{fan}, \mathrm{A}}}+\frac{F_{\mathrm{fan}, \mathrm{B}} P_{\mathrm{fan}, \mathrm{B}}}{\eta_{\mathrm{fan}, \mathrm{B}}},
$$

where $\eta_{\text {fan, } \mathrm{B}}$ and $\eta_{\text {fan, } \mathrm{A}}$ are the fan efficiencies. Only the variable frequency pump consumption was considered here, because the consumption of other pumps could be regarded as constant. The pump energy model is

$$
E_{\mathrm{pp}}=\frac{\gamma Q H_{\mathrm{p}}}{\eta_{\mathrm{pp}}}
$$

where $H_{\mathrm{p}}$ is the pump head $\left(m \mathrm{H}_{2} \mathrm{O}\right), Q$ is the volume flow rate $\left(\mathrm{m}^{3} / \mathrm{s}\right), \gamma$ is the fluid bulk density $\left(\mathrm{kN} / \mathrm{m}^{3}\right)$, and $\eta_{\mathrm{pp}}$ is the pump efficiency. The heater energy model is

$$
E_{\text {heater }}=E_{\text {heater } 1}+E_{\text {heater } 2}+E_{\text {heater } 3} \text {. }
$$

\subsection{Control strategies}

\subsubsection{Gearshift integral PID}

The basic idea of gearshift is to change the cumulative rate of integration according to the deviation size. The integration is slow with big deviations, but otherwise is fast. The algorithm is

$$
\begin{aligned}
& u(k)= K_{\mathrm{p}} e(k)+K_{\mathrm{I}}\left\{\sum_{i=0}^{k-1} e(i)+f[e(k)] e(k)\right\} \\
&+K_{\mathrm{D}}[e(k)-e(k-1)], \\
& f[e(k)]= \begin{cases}1, & |e(k)| \leq B, \\
\frac{A-|e(k)|+B}{A}, & B<|e(k)| \leq A+B, \\
0, & |e(k)|>A+B,\end{cases}
\end{aligned}
$$


where $A$ and $B$ are constants selected by the designer, $K_{\mathrm{p}}$ is proportional gain, $K_{\mathrm{I}}$ is integral gain, $K_{\mathrm{D}}$ is derivation gain, $e$ is error, and $k$ is the number of calculations. Compared to normal PID, the gearshift integration PID has the advantages of complete elimination of the integral saturation phenomenon, significantly reducing the overshoot and easily stabilizing the system, strong adaptability, easily tuned parameters, and small interaction between parameters.

Fig. 5 shows the control effect of static pressure under a normal PID control strategy and under the gearshift PID control strategy. The step response curves show that the control effect of gearshift PID is better than that of normal PID with less or even no overshoot. It removes the tendency of the signal to decline, with a sacrifice in adjustment time of less than $10 \mathrm{~s}$. In the actual project, this sacrifice had little influence on the system performance.

\subsubsection{Self-tuning PID}

Self-tuning PID is one of the most widely applied adaptive methods. The idea of a self-tuning regulator (STR) is to separate system parameter estimation from controller design. The self-tuning PID adopted here comprises three parts: recursive least square (RLS) parameter estimation, controller parameter design, and a PID regulator. The control system structure is shown in Fig. 6. The input and output of the plant were sampled online. The parameters of the plant $\theta(t)$ were estimated with RLS. The controller parameters $\theta_{\mathrm{c}}(t)$ were computed by an improved Ziegler-Nichols tuning method (Svrcek et al., 2006). Finally, the new control $u(t)$, which is also the input of the system, was obtained in the controller with system output $y(t)$, controller set point $r(t)$, and $\theta_{\mathrm{c}}(t)$. STRs are designed to depict system dynamic performance using a prediction model with known structure and unknown parameters. Then the estimated parameters are treated as the real system parameters. Thus, an STR consists of two parts, identification and control. The self-tuning capability is achieved through online identification.

1. Plant model description

For a single input single output (SISO) system, a system model can be used as defined by

$$
A\left(q^{-1}\right) y(t)=B\left(q^{-1}\right) u(t)+e(t)
$$

where

$$
\begin{gathered}
A\left(q^{-1}\right)=1+a_{1} q^{-1}+a_{2} q^{-2}+\cdots+a_{n_{a}} q^{-n_{a}}, \\
B\left(q^{-1}\right)=b_{1} q^{-1}+b_{2} q^{-2}+\cdots+b_{n_{b}} q^{-n_{b}},
\end{gathered}
$$

$a_{1}-a_{n_{a}}$ and $b_{1}-b_{n_{b}}$ are the coefficients determined by system characteristics, $n_{a}$ and $n_{b}$ together represent system order, $e(t)$ is the zero mean white noise disturbance, and $q^{-1}$ is the forward shift operator.

2. Improved Ziegler-Nichols tuning method

According to the Ziegler-Nichols tuning formula (Hang and Sin, 1991), the relationship among $K_{\mathrm{p}}, T_{\mathrm{I}}, T_{\mathrm{D}}$, the critical gain $K_{\mathrm{u}}$, and the critical oscillation period $T_{\mathrm{u}}$ is

$$
K_{\mathrm{p}}=0.6 K_{\mathrm{u}}, T_{\mathrm{I}}=0.5 T_{\mathrm{u}}, T_{\mathrm{D}}=0.125 T_{\mathrm{u}} .
$$

$K_{\mathrm{u}}$ and $T_{\mathrm{u}}$ are functions of the system parameters. The critical parameters $K_{\mathrm{u}}$ and $T_{\mathrm{u}}$ determined by test methods may result in system instability. When the system time constant is large, a long time is needed to reach the critical steady state of the system. To solve these problems, an improved ZieglerNichols method (Nassif et al., 2008) was applied.

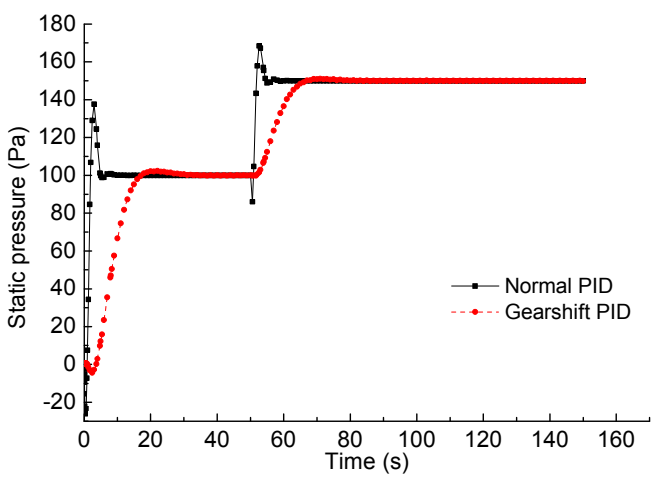

Fig. 5 Gearshift PID parameter tuning

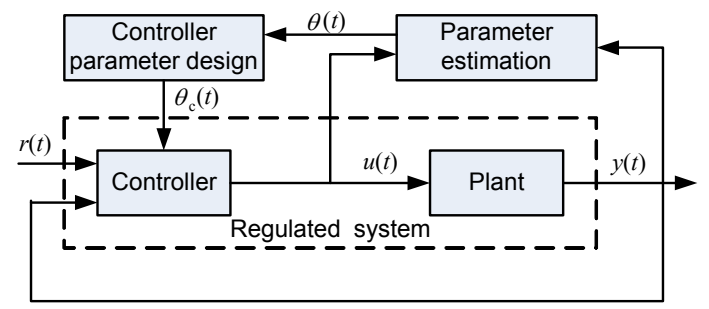

Fig. 6 Self-tuning PID control structure

\subsubsection{ILC}

ILC proposed by Yan et al. (2010b) is used before the DCL for stable-state optimization by 
imposing external control on the dynamic process (Ruan et al., 2008). The control structure of ILC (Wan, 2003) is shown in Fig. 7. $G_{\mathrm{c}}(s)$ is the transfer function of the internal controller. The output $r_{k}(t)$ of ILC, where the subscript $k$ is the iterative number, is the set point of the DCL, while the DCL is composed of a PID controller (such as a gearshift integral PID and a self-tuning PID) and an object. It is a double closed loop control system. Dynamic response is controlled by an internal loop controller. The set point series is optimally adjusted by the external ILC. The closed loop equation is

$$
\begin{aligned}
& \dot{x}(t)=f(x(t), u(t), t), \\
& y(t)=g(x(t), u(t), t),
\end{aligned}
$$

where $f(\cdot)$ and $g(\cdot)$ are nonlinear functions, $t$ represents time, and $x(t), u(t)$, and $y(t)$ represents state variables, control variables, and output variables of the control system, respectively.

The controller's setting series, optimized from the optimization layer, is supposed to be $c_{1}, c_{2}, \ldots$, $c_{k}, c_{k+1}$. The subscript $k$ is the iterative number, and $y_{k}(t)$ is the system output at the $k$ th iterative. $y_{d_{k}}(t)$ is the desired trajectory determined by $c_{k}$, while $c_{k}$ is the result of the optimization layer. $r_{k}(t)$ is the set value calculated by ILC. When $c_{k+1}$ is applied to the system, $r_{k+1}(t)$ can be gained according to the basic PID-type open-loop (Eq. (24)) or closed-loop (Eq. (25)) iterative algorithms:

$$
\begin{aligned}
r_{k+1}(t)= & \alpha_{k+1} r_{k}(t)+\alpha_{k+1} \Gamma_{\mathrm{p}} e_{k}(t) \\
& +\alpha_{k+1} \Gamma_{\mathrm{i}} \int e_{k}(\mu) \mathrm{d} \mu+\alpha_{k+1} \Gamma_{\mathrm{d}} \dot{e}_{k}(t), \\
r_{k+1}(t)= & \alpha_{k+1} r_{k}(t)+\Gamma_{\mathrm{p}} e_{k+1}(t) \\
& +\Gamma_{\mathrm{i}} \int e_{k+1}(\mu) \mathrm{d} \mu+\Gamma_{\mathrm{d}} \dot{e}_{k+1}(t),
\end{aligned}
$$

where $\alpha_{k+1}=\frac{c_{k+1}}{c_{k}}$ is a weighting coefficient, and

$$
e_{k}(t)=y_{d_{k}}(t)-y_{k}(t)
$$

$\Gamma_{\mathrm{P}}, \Gamma_{\mathrm{i}}$, and $\Gamma_{\mathrm{d}}$ is the proportional, integral, and differential gain, respectively.

The desired trajectory is

$$
y_{d_{k}}(t)=\left(c_{k}-c_{k-1}\right)\left(1-\mathrm{e}^{-\alpha t}\right)+c_{k-1}, \quad k=2,3, \cdots
$$

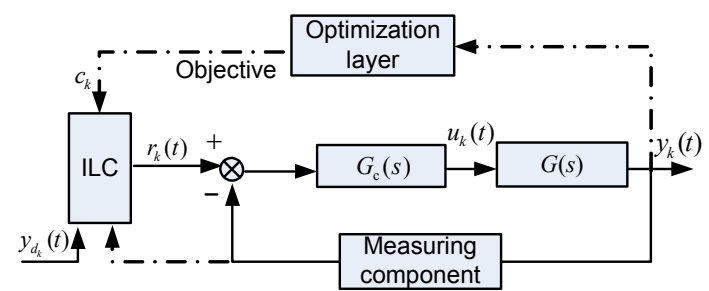

Fig. 7 Control structure of ILC

Taking variable frequency fan-static pressure control loop in AHUB as the object, the supply fan frequency is the control input while the duct static pressure is the output (Yan et al., 2010b). Eq. (28) was adopted as the simulation model:

$$
G(s)=\frac{5.2457}{4.3617 s^{2}+4.177 s+1} .
$$

The transfer function of the internal controller can then be calculated as

$$
G_{\mathrm{c}}(s)=1.1563\left(1+\frac{1}{2.287 s}+0.5718 s\right) .
$$

The step set point change sequence for the subsystem, which is the output of the LDMU, is

$c=\left[\begin{array}{lllllllll}1.0 & 1.2 & 0.9 & 1.3 & 1.2 & 1.7 & 1.8 & 1.6 & 1.9\end{array}\right] \times 100 \mathrm{~Pa} .(30)$

The desired trajectory of the subsystem is

$$
y_{d_{k}}(t)=\left(c_{k}-c_{k-1}\right)\left(1-\mathrm{e}^{-\alpha t}\right)+c_{k-1}, \quad k=2,3, \cdots
$$

The open-loop proportional-derivative (PD)type ILC method is taken for the above control loop. The learning gains are $\Gamma_{\mathrm{P}}=0.5, \Gamma_{\mathrm{i}}=0$, and $\Gamma_{\mathrm{d}}=4$, respectively. The control signals and corresponding responses to the control method of ILC and PID of the fan control loop are shown in Fig. 8. In Fig. 8a at the beginning, the system has the same output for normal PID and ILC, because there is no iteration for open-loop ILC at first (Yan et al., 2010b).

The system with ILC has better dynamic performance and faster response after several iterations. It is concluded that system has better dynamic performance with ILC than with normal PID method. At each period, the steady state of $r_{k}(t)$ reaches the desired value as shown in Fig. 8b. 

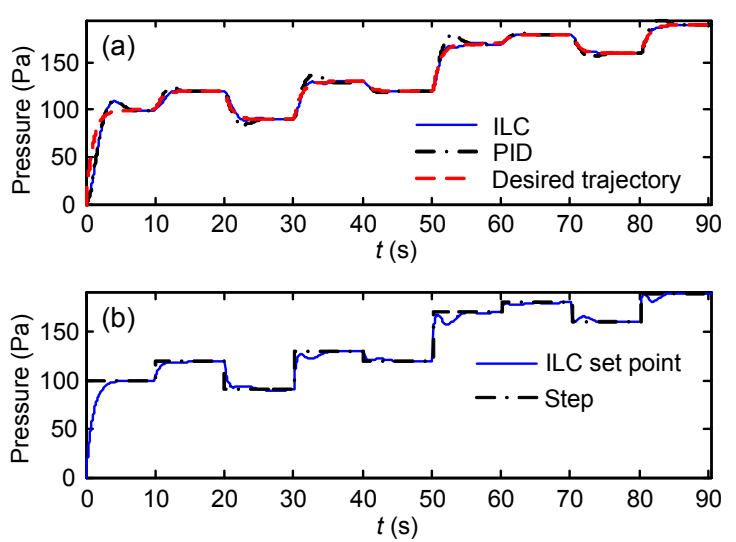

Fig. 8 Simulation results for ILC

(a) Responses of the ILC strategy and step function-type;

(b) Steady state of ILC control input and step input

\section{Results}

\subsection{Single control loop}

For the system application, modeling is not the ultimate goal but serves for control demand. The performance of the above control loops can be seen in the following. Here, the response time of the controller is about $1 \mathrm{~ms}$. The accuracies, or accuracy classes, of sensors are listed in Table 1.

\subsubsection{Secondary pump differential pressure control}

Pressure changes quickly in the secondary pump control loop. Sampling time is $1 \mathrm{~s}$. Fig. 9a shows the control effect when the set point is 0.05 MPa. Under the PID controller, the differential pressure is stable near the set point, showing that the controller has good performance. The control input is shown in Fig. 9b.

When the load of AHUB does not change, the damper B (Fig. 1) maintains at about 50\%. At the same time, damper A (Fig. 1) is also 50\% under some load. When the set point of the secondary pump pressure suddenly changes from $0.05 \mathrm{MPa}$ to $0.055 \mathrm{MPa}$, the measured value reaches $0.055 \mathrm{MPa}$ swiftly under the closed control effect (Fig. 10). Damper A opening changes from $50 \%$ to $20 \%$ after $226 \mathrm{~s}$, then from $20 \%$ to $10 \%$ after $457 \mathrm{~s}$ and from $10 \%$ to $30 \%$ after $745 \mathrm{~s}$ (Fig. 10). These changes are in response to load changes. The secondary pump differential pressure is maintained at $0.055 \mathrm{MPa}$, because after sudden changes of damper $\mathrm{A}$, the frequency of the secondary pump changes due to the closed control effect. So the differential pressure can track the set point quickly. The changing trend of frequency is the same as that of the total flow of supply and return water.

Table 1 Sensor accuracy

\begin{tabular}{lc}
\hline \multicolumn{1}{c}{ Name } & Accuracy/Accuracy class \\
\hline Temperature sensor & $\pm 0.5{ }^{\circ} \mathrm{C}$ \\
Humidity sensor & $\pm 3 \% \mathrm{RH}$ \\
Static pressure & $\pm 1 \%$ \\
$\mathrm{CO}_{2}$ & $\pm(40 \mathrm{ppm}+3 \%$ measured value $)$ \\
Air flow velocity & $10 \mathrm{~m} / \mathrm{s}: \pm(0.2 \mathrm{~m} / \mathrm{s}+3 \%$ measured value $)$ \\
& $15 \mathrm{~m} / \mathrm{s}: \pm(0.3 \mathrm{~m} / \mathrm{s}+3 \%$ measured value $)$ \\
& $20 \mathrm{~m} / \mathrm{s}: \pm(0.3 \mathrm{~m} / \mathrm{s}+4 \%$ measured value $)$ \\
Water temperature & $\pm 0.5 \%$ \\
$\quad$ sensor & 0.5 \\
Water flow sensor & 0.25 \\
Pressure differen- & \\
tial sensor & \\
\hline
\end{tabular}
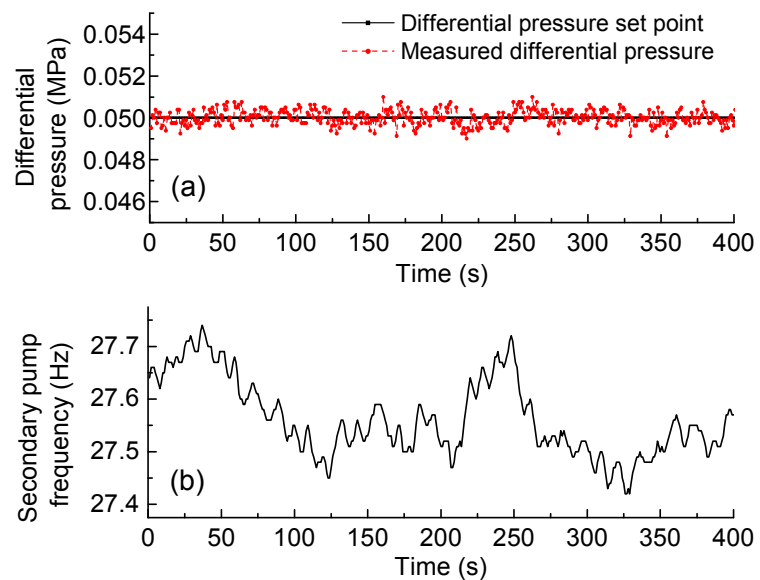

Fig. 9 Control performance of secondary pump differential pressure

(a) Secondary pump differential pressure; (b) Frequency of secondary pump

\subsubsection{Air supply temperature control}

Taking the air supply temperature control of AHUA as an example, the experimental results are shown in Fig. 11. The set point is $28.5^{\circ} \mathrm{C}$ and the sampling time is $5 \mathrm{~s}$. The temperature fluctuations around the set point are caused by the damper characteristics and water temperature fluctuations. The control signal changes every $30 \mathrm{~s}$ to prevent frequent action of the damper. 


\subsubsection{Static pressure control}

The static pressure loop adopts adaptive PID control strategy. The controller has different parameters in different conditions. The control effect is shown in Figs. 12 and 13. The set point of AHUA changes from $180 \mathrm{~Pa}$ to $185 \mathrm{~Pa}$, then from $185 \mathrm{~Pa}$ to $180 \mathrm{~Pa}$. The set point of AHUB changes from $140 \mathrm{~Pa}$ to $150 \mathrm{~Pa}$ after $600 \mathrm{~s}$, then from $150 \mathrm{~Pa}$ to $140 \mathrm{~Pa}$. The control results show that the two systems have a good controlling effect under different working conditions. In the early stages of the set point changing, there is little or no overshoot thanks to the adaptive controller. The whole system has a good tracking result.

The duct static pressure is influenced by the changes of the damper opening of VAV box. Fig. 14 shows the closed pressure control under the load change when the set point is $190 \mathrm{~Pa}$. The damper opening is the feedback value. The sudden change of damper opening is a bad value caused by
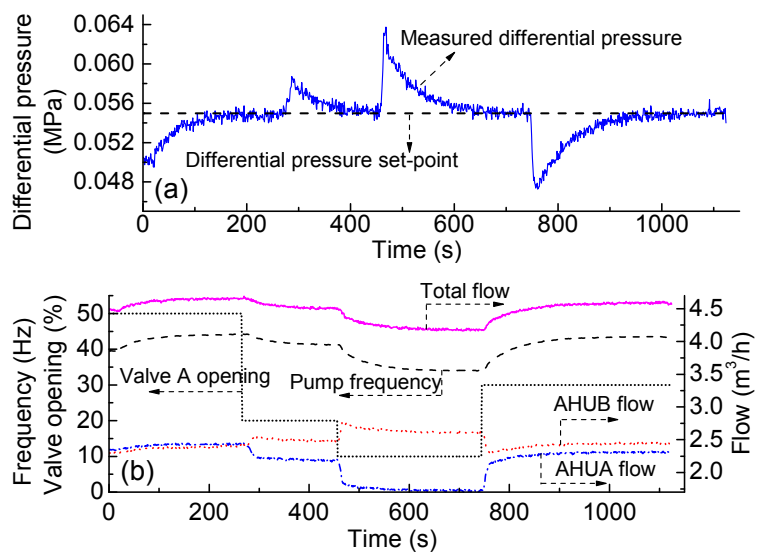

Fig. 10 Secondary pressure control under disturbance of valve opening
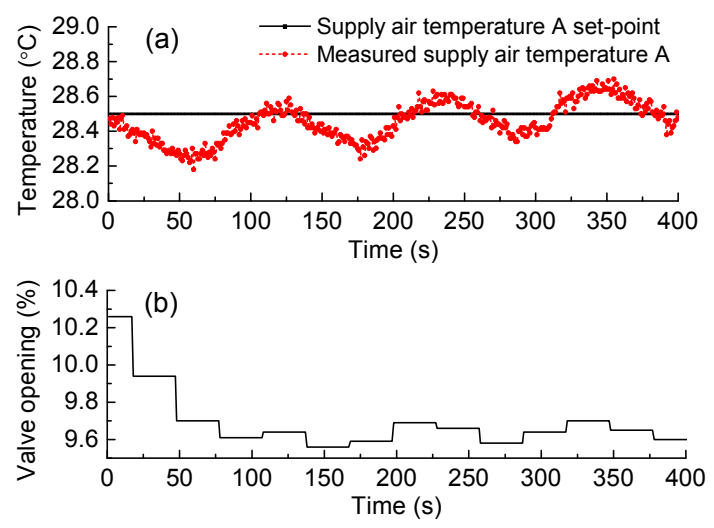

Fig. 11 AHUA supply air temperature voltage fluctuations of the acquisition card. The damper opening of VAV box changes according to load changes. After $46 \mathrm{~s}$, the damper opening
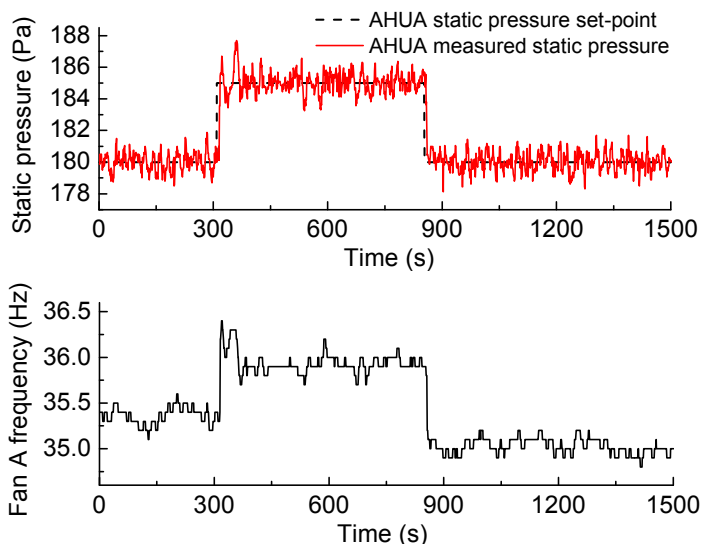

Fig. 12 AHUA duct static pressure control
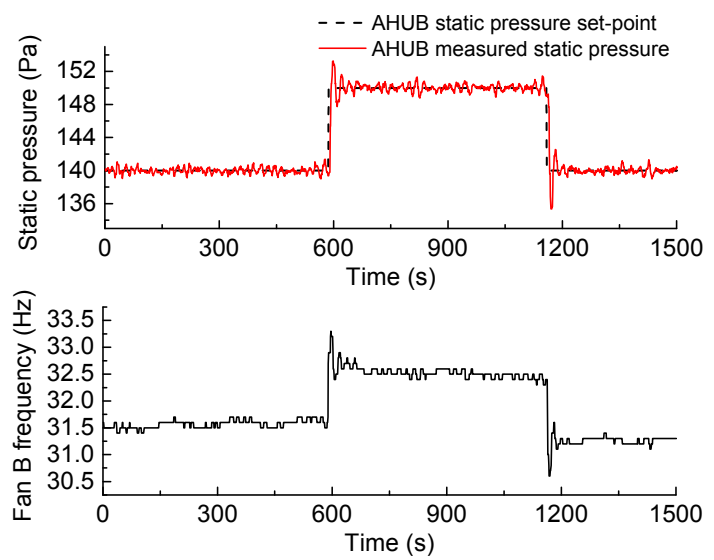

Fig. 13 AHUB duct static pressure control
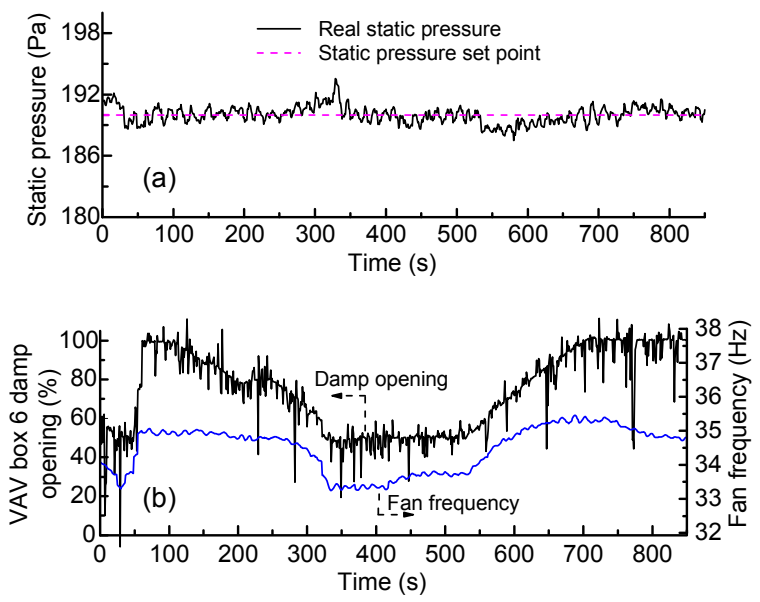

Fig. 14 Closed-loop control of VAV box 6 in AHUB

(a) Static pressure; (b) VAV box 6 damp opening 
gradually opens from $50 \%$ to $100 \%$ due to the load increase (Fig. 14b). Then the static pressure decreases. But the fan frequency begins to increase under the closed control strategy to maintain the static pressure set point (Fig. 14a). Effective closedloop control is realized through the above analysis.

\subsection{Optimization}

With $c=\left[\begin{array}{llllll}50 & 45 & 40 & 25 & 35 & 30\end{array}\right] \mathrm{Pa}$ as set point series, the test was carried out based on the above simulation. From results as shown in Fig. 15, we could know that due to quick response, sensor sensitivity, and environmental disturbance, the measured static pressure was not stable, while the average of static pressure was still stable (Yan et al., 2010b).

The experiment results for one day (Fig. 16) show that all devices work under coordinated conditions with a "decomposition and coordination" strategy under variable loads, and that energy savings could be achieved with the global optical control.

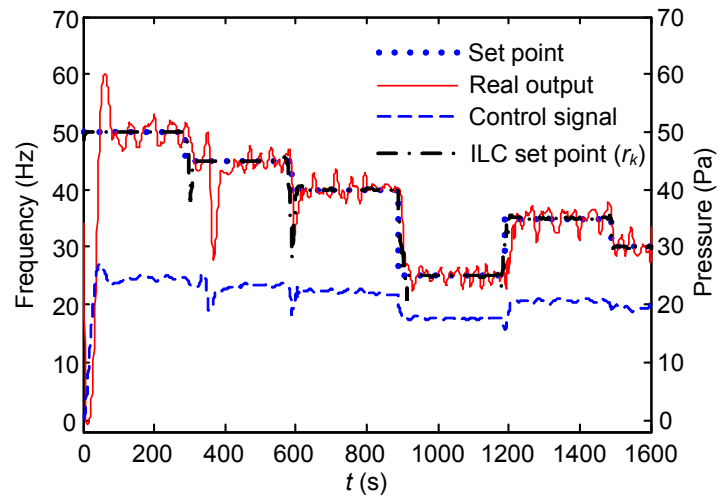

Fig. 15 Experimental results for ILC

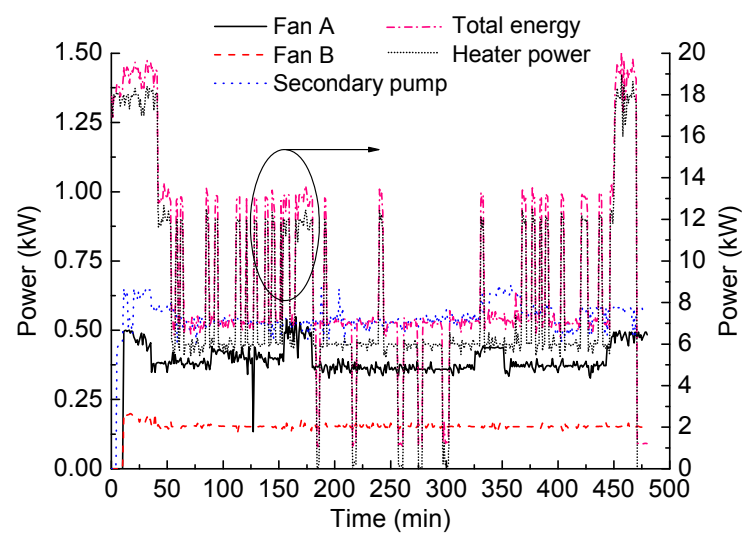

Fig. 16 Energy consumption for one day

\section{Conclusions}

Models of the main control loops, the secondary pump differential pressure, static pressure, and air supply temperature, were derived using ADF method in a versatile, seamless, and effective airconditioning system. The power of the system is that many modeling methods and control strategies can be implemented. Then, gearshift integral PID, self-tuning PID, and iterative learning control were studied in the air-conditioning system. The integrated control of the above strategies, the iterative learning control, interaction balance method, and the optimization method of sequential quadratic programming (Yan et al., 2010a) resulted in an 18.2\% energy saving in the whole system (based on a single day's data). How to coordinate the control loops is a big problem for application in a real system and requires further research. HVAC is a dynamic system, and sudden changes, such as opening of doors and windows or fluctuations in indoor occupant numbers, have great effects on indoor contaminant concentration (Myhren and Holmberg, 2008). How to deal with such dynamic situations in buildings is our future research issue.

\section{References}

Afram, A., Janabi-Sharifi, F., 2014. Review of modeling methods for HVAC systems. Applied Thermal Engineering, 67(1-2):507-519. [doi:10.1016/j.applthermaleng. 2014.03.055]

Anderson, M., Buehner, M., Young, P., et al., 2007. An experimental system for advanced heating, ventilating and air conditioning (HVAC) control. Energy and Buildings, 39(2):136-147. [doi:10.1016/j.enbuild.2006.05.003]

Barbosa, R.M., Mendes, N., 2008. Combined simulation of central HVAC systems with a whole-building hygrothermal model. Energy \& Buildings, 40(3):276-288. [doi:10.1016/j.enbuild.2007.02.022]

Blume, P.A., 2007. The LabVIEW Style Book. Pearson Education, San Antonio, USA.

Cho, Y.H., Wang, G., Liu, M., 2010. Application of terminal box optimization of single-duct air-handling units. International Journal of Energy Research, 34(1):54-66. [doi:10.1002/er.1544]

Fong, K.F., Hanby, V.I., Chow, T.T., 2006. HVAC system optimization for energy management by evolutionary programming. Energy and Buildings, 38(3):220-231. [doi:10.1016/j.enbuild.2005.05.008]

Hang, C.C., Sin, K.K., 1991. A comparative performance study of PID auto-tuners. Control Systems, IEEE, 11(5): 41-47. [doi:10.1109/37.90541] 
Hu, Q., Albert, T.P., Tse, W.L., et al., 2005. Development of ANN-based models to predict the static response and dynamic response of a heat exchanger in a real HVAC system. Journal of Physics: Conference Series, 23:110121.

Huang, W., Zaheeruddin, M., Cho, S.H., 2006. Dynamic simulation of energy management control functions for HVAC systems in buildings. Energy Conversion and Management, 47(7-8):926-943. [doi:10.1016/j.enconman. 2005.06.011]

Kulhavý, R., 1987. Restricted exponential forgetting in realtime identification. Automatica, 23(5):589-600. [doi:10. 1016/0005-1098(87)90054-9]

Kusiak, A., Tang, F., Xu, G., 2011. Multi-objective optimization of HVAC system with an evolutionary computation algorithm. Energy, 36(5):2440-2449. [doi:10.1016/ j.energy.2011.01.030]

Kwok, S.S.K., Lee, E.W.M., 2011. A study of the importance of occupancy to building cooling load in prediction by intelligent approach. Energy Conversion and Management, 52(7):2555-2564. [doi:10.1016/j.enconman.2011. 02.002]

Lennart, L., 1999. System Identification-Theory for the User, 2nd Edition. Prentice Hall, New Jersey, USA.

Ma, Z., Wang, S., 2011. Supervisory and optimal control of central chiller plants using simplified adaptive models and genetic algorithm. Applied Energy, 88(1):198-211. [doi:10.1016/j.apenergy.2010.07.036]

Mossolly, M., Ghali, K., Ghaddar, N., 2009. Optimal control strategy for a multi-zone air conditioning system using a genetic algorithm. Energy, 34(1):58-66. [doi:10.1016/j. energy.2008.10.001]

Myhren, J.A., Holmberg, S., 2008. Flow patterns and thermal comfort in a room with panel, floor and wall heating. Energy and Buildings, 40(4):524-536. [doi:10.1016/j. enbuild.2007.04.011]

Nassif, N., 2010. Performance analysis of supply and return fans for HVAC systems under different operating strategies of economizer dampers. Energy and Buildings, 42(7):1026-1037. [doi:10.1016/j.enbuild.2010.01.015]

Nassif, N., Moujaes, S., 2008. A new operating strategy for economizer dampers of VAV system. Energy and Buildings, 40(3):289-299. [doi:10.1016/j.enbuild.2007. 02.030]

Nassif, N., Moujaes, S., Zaheeruddin, M., 2008. Self-tuning dynamic models of HVAC system components. Energy and Buildings, 40(9):1709-1720. [doi:10.1016/j.enbuild. 2008.02.026]

Platt, G., Li, J., Li, R., et al., 2010. Adaptive HVAC zone modeling for sustainable buildings. Energy and Buildings, 42(4):412-421. [doi:10.1016/j.enbuild.2009.10.009]

Ruan, X.E., Bien, Z.Z., Park, K.H., 2008. Decentralized iterative learning control to large-scale industrial processes for nonrepetitive trajectory tracking. IEEE Transactions on Systems, Man, and Cybernetics-Part A: Systems and Humans, 38(1):238-252. [doi:10.1109/TSMCA.2007. 909549]

Svrcek, W.Y., Mahoney, D.P., Young, B.R., 2006. A Realtime Approach to Process Control, 2nd Edition. John
Wiley \& Sons, New Jersey, USA.

Wan, B.W., 2003. Industrial Large-scale System Optimization \& Product Quality Control. Science Press, Beijing, China (in Chinese).

Wang, S.W., Ma, Z.J., 2008. Supervisory and optimal control of building HVAC systems: a review. HVAC\&R Research, 14(1):3-32. [doi:10.1080/10789669.2008. 10390991]

Wang, S.W., Sun, Z., Sun, Y., et al., 2011. Online optimal ventilation control of building air-conditioning systems. Indoor and Built Environment, 20(1):129-136. [doi:10. 1177/1420326X10394491]

West, S.R., Ward, J.K., Wall, J., 2014. Trial results from a model predictive control and optimisation system for commercial building HVAC. Energy and Buildings, 72: 271-279. [doi:10.1016/j.enbuild.2013.12.037]

Yan, X., Ren, Q., Meng, Q., 2010a. Global optimization of VAV air conditioning system. Proceeding of the 8th World Congress on Intelligent Control and Automation, Jinan, China, p.5077-5081.

Yan, X., Ren, Q., Meng, Q., 2010b. Iterative learning control in large scale HVAC system. Proceeding of the 8th World Congress on Intelligent Control and Automation, Jinan, China, p.5063-5066.

Zhang, H.G., Cai, L.L., 2002. Decentralized nonlinear adaptive control of an HVAC system. IEEE Transactions on Systems, Man, and Cybernetics, Part C: Applications and Reviews, 32(4):493-498. [doi:10.1109/TSMCC. 2002.807271]

\section{中文概要}

题 目: 基于迭代学习的变风量空调系统全局优化控制 实验研究

目 的: 采用实验方法研究变风量全局优化问题, 利用 迭代学习控制策略优化动态控制性能, 获得变 风量系统在系统层次的最优。

创新点: 1. 采用全新的兼有变风量和变水量功能的实验 平台；2. 引入递阶优化控制理论, 建立变风量 系统的动态和稳态模型; 3. 采用先进控制策 略, 如自校正比例积分微分（PID）控制和迭代 学习控制等。

方 法: 1. 将系统进行分解 (图 4), 并建立系统稳态模 型 (公式 6-11)、动态模型 (公式 12-15) 和能 耗模型（公式 16）；2. 在此基础上采用变速积 分 PID、自校正 PID 和迭代学习控制对系统底 层进行动态控制, 在系统整体优化中引入迭代 学习。

结 论：1. 先进控制策略的引入有利于优化变风量系统 动态控制过程; 2. 采用基于迭代学习的优化方 法，可使系统节能约 18.2\%。

关键词: 空调; 大系统; 迭代学习控制; 全局优化 